JAMA Pediatrics | Original Investigation

\title{
Effectiveness of Computer Automation for the Diagnosis and Management of Childhood Type 2 Diabetes A Randomized Clinical Trial
}

Tamara S. Hannon, MD, MS; Tamara M. Dugan, MS; Chandan K. Saha, PhD; Steven J. McKee, BS; Stephen M. Downs, MD, MS; Aaron E. Carroll, MD, MS

IMPORTANCE Type 2 diabetes (T2D) is increasingly common in young individuals. Primary prevention and screening among children and adolescents who are at substantial risk for T2D are recommended, but implementation of $\mathrm{T} 2 \mathrm{D}$ screening practices in the pediatric primary care setting is uncommon.

OBJECTIVE To determine the feasibility and effectiveness of a computerized clinical decision support system to identify pediatric patients at high risk for T2D and to coordinate screening for and diagnosis of prediabetes and T2D.

DESIGN, SETTING, AND PARTICIPANTS This cluster-randomized clinical trial included patients from 4 primary care pediatric clinics. Two clinics were randomized to the computerized clinical decision support intervention, aimed at physicians, and 2 were randomized to the control condition. Patients of interest included children, adolescents, and young adults 10 years or older. Data were collected from January 1, 2013, through December 1, 2016.

INTERVENTIONS Comparison of physician screening and follow-up practices after adding a T2D module to an existing computer decision support system.

MAIN OUTCOMES AND MEASURES Electronic medical record (EMR) data from patients 10 years or older were reviewed to determine the rates at which pediatric patients were identified as having a body mass index (BMI) at or above the 85th percentile and 2 or more risk factors for T2D and underwent screening for T2D.

RESULTS Medical records were reviewed for 1369 eligible children ( 712 boys [ $52.0 \%$ ] and 657 girls [48.0\%]; median [interquartile range] age, 12.9 [11.2-15.3]), of whom 684 were randomized to the control group and 685 to the intervention group. Of these, 663 (48.4\%) had a BMI at or above the 85th percentile. Five hundred sixty-five patients (41.3\%) met T2D screening criteria, with no difference between control and intervention sites. The T2D module led to a significant increase in the percentage of patients undergoing screening for T2D (89 of 283 [31.4\%] vs 26 of 282 [9.2\%]; adjusted odds ratio, 4.6; $95 \% \mathrm{Cl}, 1.5-14.7$ ) and a greater proportion attending a scheduled follow-up appointment (45 of 153 [29.4\%] vs 38 of 201 [18.9\%]; adjusted odds ratio, $1.8 ; 95 \% \mathrm{Cl}, 1.5-2.2$ ).

CONCLUSIONS AND RELEVANCE Use of a computerized clinical decision support system to automate the identification and screening of pediatric patients at high risk for T2D can help overcome barriers to the screening process. The support system significantly increased screening among patients who met the American Diabetes Association criteria and adherence to follow-up appointments with primary care clinicians.

TRIAL REGISTRATION clinicaltrials.gov Identifier: NCT01814787
Journal Club Slides and Supplemental content

CME Quiz at

jamanetworkcme.com and CME Questions page 403
Author Affiliations: Indiana Children's Health Services Research, Department of Pediatrics, Indiana University School of Medicine, Indianapolis (Hannon, Dugan, McKee, Downs, Carroll); Department of Biostatistics, Indiana University School of Medicine, Indianapolis (Saha).

Corresponding Author: Tamara S Hannon, MD, MS, Department of Pediatrics, Indiana University School of Medicine, 410 W 10th St, Ste 2000, Indianapolis, IN 46202 (tshannon@iu.edu). 
$\mathrm{T}$ he American Diabetes Association (ADA) recommends screening among children, adolescents, and young adults 10 years or older (hereinafter referred to as youths) who are at risk for type 2 diabetes (T2D). ${ }^{1}$ The ADA also recommends primary prevention efforts, such as lifestyle modification, be directed to individuals whose glucose levels are elevated but not diagnostic of diabetes (ie, prediabetes). ${ }^{2}$

Although consensus exists regarding screening for T2D in youths at high risk for disease, implementation in the primary care setting is not ideal. ${ }^{3,4}$ Barriers to screening include physician time constraints, lack of knowledge about screening and management guidelines, lack of educational tools to help communicate with patients and families, and failure to complete testing and attend follow-up appointments. ${ }^{3,4}$

We implemented the ADA screening guidelines for T2D at pediatric primary care practices by using a computer decision support system developed by our research group: the Child Health Improvement Through Computer Automation (CHICA) system. ${ }^{5}$ The application of a computer decision support system to the screening and diagnosis of T2D in youths is relatively unexplored. ${ }^{3}$ We hypothesized that the system could help overcome the barriers to screening for prediabetes and T2D described by pediatricians. Our objective was to determine the feasibility and effectiveness of the CHICA system in identifying at-risk youths and coordinating the screening for and diagnosis of prediabetes and T2D via a randomized clinical trial.

\section{Methods}

This study was performed in 4 primary care practices in the Eskenazi Health Center Primary Care system from January 1, 2013, through December 1, 2016. The trial protocol (available in the Supplement) was approved by the institutional review board of Indiana University. A waiver of consent was obtained from the institutional review board because (1) little risk accrued in supplying physicians with guidelines; (2) study procedures were within the standards of care; (3) informing families that they may be part of a study could bias their response to screening questions; and (4) obtaining informed consent from every patient was impracticable and presented a higher risk for loss of patient confidentiality.

\section{Participants}

Our intervention was aimed at physicians. However, the outcomes of interest are patient based. The patients in this study were 10 years or older and were automatically cluster randomized to the control or the intervention group based on which of the 4 clinics they attended. No patients were contacted by researchers, their physician, or other staff regarding the study. The ADA recommends that youths be screened for T2D if they have a body mass index (BMI) (calculated as weight in kilograms divided by height in meters squared) at or above the 85th percentile for age and sex and 2 or more additional risk factors starting at 10 years of age or at the onset of puberty, whichever occurs first. ${ }^{1}$

\section{Key Points}

Question Can use of a computerized clinical decision support system help decrease barriers to screening for and diagnosis of prediabetes and type 2 diabetes in pediatric patients?

Findings In this cluster-randomized clinical trial performed in 4 pediatric clinics that included 1369 patients, computerized clinical decision support significantly increased the rates of screening for prediabetes and type 2 diabetes among pediatric patients meeting the risk criteria compared with patients in a control group of clinics.

Meaning Use of a computerized clinical decision support system can help overcome barriers and significantly increase the rates of screening and clinical follow-up for prediabetes and type 2 diabetes in pediatric patients.

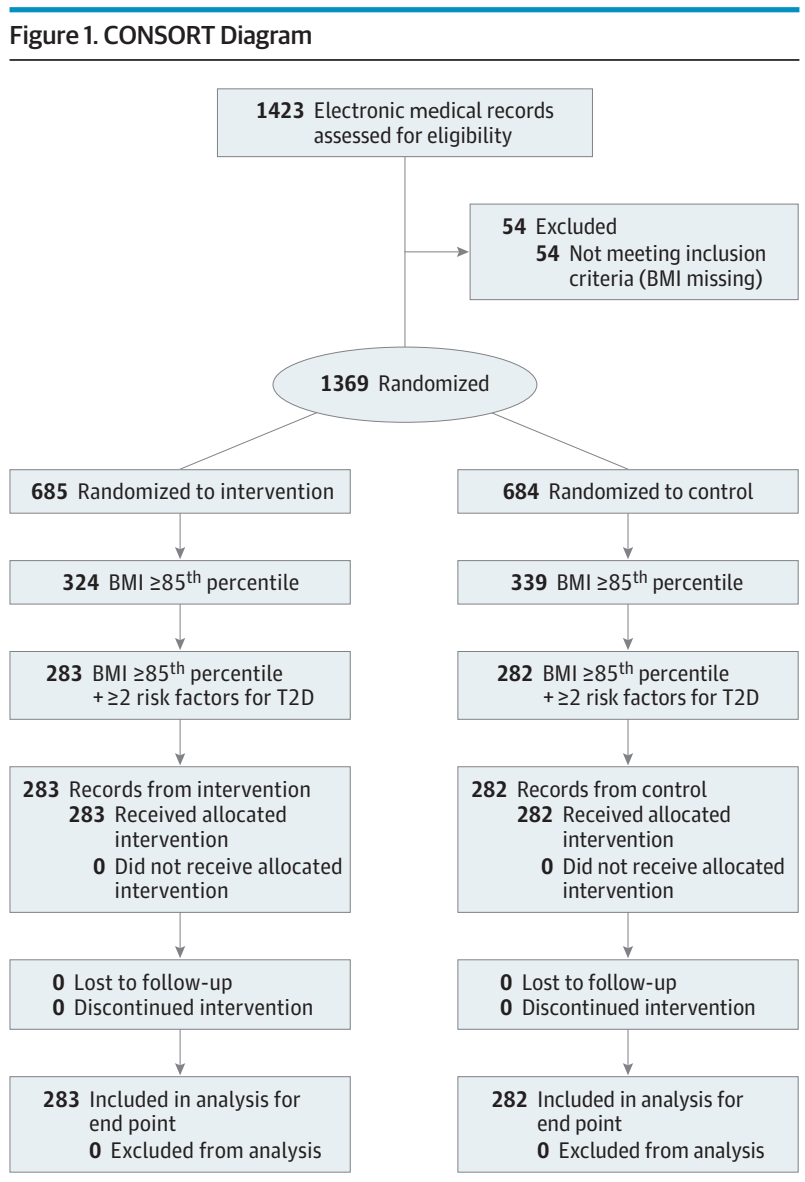

The final analysis included 565 patients with risk factors for type 2 diabetes (T2D). BMI indicates body mass index.

Study Design

We conducted a cluster-randomized clinical trial in which we compared screening for T2D among youth meeting ADA criteria between the intervention and control practices (Figure 1). Four clinics were enrolled by randomizing the 2 largest clinics to the intervention and control conditions by a coin toss. Two additional clinics were alternately assigned to the intervention and control conditions such that study populations 
Figure 2. Screening in Pediatrician's Office With Child Health Improvement Through Computer Automation (CHICA) Type 2 Diabetes (T2D) Module
Includes patients 10 years or older. BMI indicates body mass index (calculated as weight in kilograms divided by height in meters squared); FPG, fasting plasma glucose: $\mathrm{GD}$, gestational diabetes; and $\mathrm{HbA}_{1 \mathrm{c}}$ hemoglobin $\mathrm{A}_{1 c}$. would be similar in size. Intervention clinics used the system that incorporated the CHICA T2D module, which included T2D guidelines. Control clinics used the traditional CHICA system that did not include T2D guidelines. Seventeen physicians practiced at the intervention sites and 12 practiced at the control sites. Although randomization at the physician or patient level may have been sample-size efficient, we randomized by clinic because contamination was a concern. If we randomized by physician, the study would be complicated when patients were seen by different physicians in and out of the study. If we randomized by patient, the on-and-off use of the CHICA T2D module would complicate physician work flow. ${ }^{6}$ Both randomization methods could lead to contamination.

\section{CHICA System}

The CHICA system has been described in detail previously. ${ }^{5,7-10}$ CHICA is a computer decision support system coupled with an electronic medical record (EMR) for pediatric primary care and chronic disease management. CHICA uses a prescreener form containing 20 questions for parents. Questions are based on national guidelines, and selection is determined by applying logic rules to data contained in the individual's EMR. ${ }^{7}$ A physician worksheet contains as many as 6 prompts that include check box responses for the physician's assessment and actions. The prescreener questions and physician prompts are programmatically chosen by the patient's age and EMR data. The CHICA T2D module prescreener included information on family history, race or ethnicity, and maternal gestational diabetes, and physician prompts included documenting signs and conditions associated with insulin resistance. The EMR contained diagnostic codes, orders, prescriptions, and laboratory data from the statewide health information exchange, the Indiana Network for Patient Care. ${ }^{11}$ CHICA was implemented on tablets for the prescreener form, and the physician worksheet switched from a paper to an online format during the study.

\section{Intervention: The CHICA T2D Module}

The outline for the CHICA T2D module is provided in Figure 2 and Figure 3. The BMI data were analyzed by the CHICA system; when the BMI was at or above the 85th percentile, a prompt on the physician worksheet asked whether the patient had any symptoms or conditions associated with insulin resistance. This information was analyzed along with the data from the prescreener form to determine whether the patient had 2 or more risk factors for T2D. If at least 2 risk factors were present, the physician was prompted to order measurement of fasting plasma glucose (FPG) and hemoglobin $\left(\mathrm{HbA}_{1 \mathrm{c}}\right)$ levels. Measurements of both FPG and $\mathrm{HbA}_{1 \mathrm{C}}$ levels were included because whether similar FPG and $\mathrm{HbA}_{1 \mathrm{C}}$ cutoff points are appropriate for the pediatric and adult populations remains unclear, and controversy exists over which is the most appropriate screening test in pediatrics. ${ }^{4,12,13}$ Paper educational materials regarding the importance of screening for T2D and instructions for the blood test were printed and provided to families. The CHICA T2D module generated automated telephone calls about laboratory testing (with instructions for fasting) and follow-up appointments. Reminder telephone calls were unique to the CHICA T2D module.

If the FPG level was greater than $125 \mathrm{mg} / \mathrm{dL}$ (to convert to millimoles per liter, multiply by 0.0555 ) or the $\mathrm{HbA}_{1 \mathrm{C}}$ level was at least $6.5 \%$ (diabetes range; to convert to a proportion of total hemoglobin, multiply by 0.01 ), a prompt instructed the 
Figure 3. Diagnosis and Management of Type 2 Diabetes (T2D) Risk With Child Health Improvement Through Computer Automation (CHICA) T2D Module

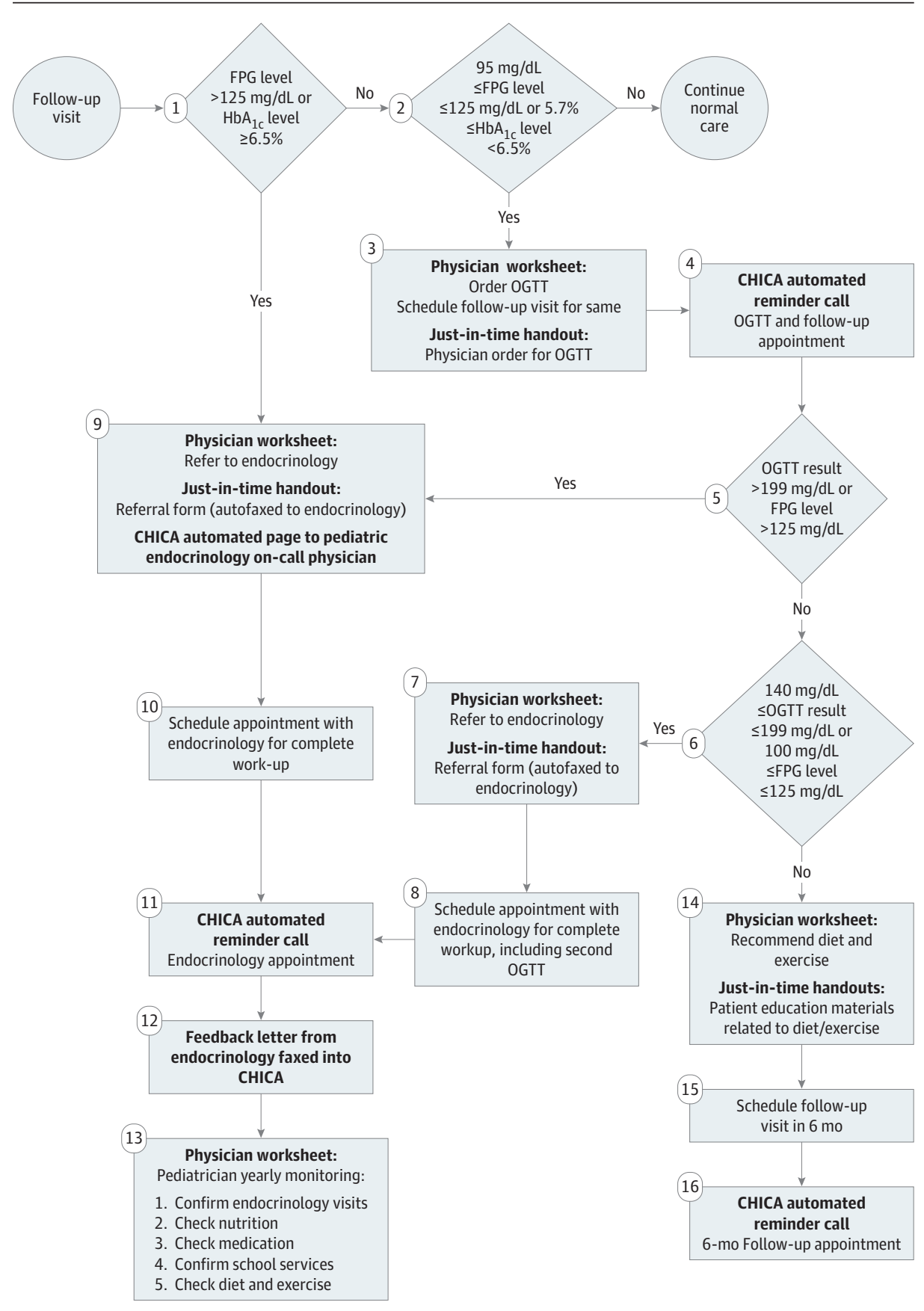

Includes patients who met criteria for T2D screening. FPG indicates fasting plasma glucose; $\mathrm{HbA}_{1 \mathrm{c}}$, hemoglobin $\mathrm{A}_{1 c}$; and OGTT, oral glucose tolerance test. To convert OGTT test results to millimoles per liter, multiply by 0.0555 .

physician to refer the patient to pediatric endocrinology for further evaluation and/or treatment; a referral page was generated if the physician responded yes to the prompt. If screening results were at or near the prediabetes range (ie, FPG level of $95-125 \mathrm{mg} / \mathrm{dL}$ and $\mathrm{HbA}_{1 \mathrm{c}}$ level $<6.5 \%$ or FPG level $\leq 125 \mathrm{mg} / \mathrm{dL}$ and $\mathrm{HbA}_{1 \mathrm{c}}$ level of 5.7\%-6.4\%), a prompt was generated for the physician to order an oral glucose tolerance test (OGTT) and follow-up appointment. The rationale for the OGTT at these FPG and $\mathrm{HbA}_{1 \mathrm{c}}$ cut points was that the reference standard for the diagnosis of prediabetes and T2D in youth is unknown and additional information on glucose tolerance would be helpful in determining risk and treatment. ${ }^{14}$ We used 95 rather than $100 \mathrm{mg} / \mathrm{dL}$ as the cut point for FPG level because this population was at high risk for T2D, and the FPG level is often not elevated in prediabetes and early T2D, when hyperglycemia occurs only in the postprandial state. ${ }^{15}$ If the OGTT result indicated diabetes (OGTT result, $>199 \mathrm{mg} / \mathrm{dL}$ ), a prompt instructed the physician to refer the patient to pediatric endocrinology, and a referral was faxed if the physician responded yes to the prompt. 
For screening test results consistent with prediabetes, the pediatrician was prompted to order a 6-month follow-up appointment. If an appointment was scheduled, the CHICA T2D module generated a reminder telephone call about this appointment. During follow-up appointments, the pediatrician was prompted to provide the patient and the patient's parent or guardian with nutrition and exercise recommendations, and paper educational handouts related to these topics were generated. If patients did not attend follow-up appointments, these handouts were not provided.

\section{Main Outcomes}

The primary outcome was the percentage of youths identified with documented risk factors for T2D. We hypothesized that the use of the prescreener form would result in the identification of more risk factors and therefore identify more youths at risk. To determine which youths were truly at risk (regardless of physician identification), data were collected via EMR abstraction and review of CHICA data for the intervention and control clinics. A random sample of 350 EMRs of youths 10 years or older per clinic was used for a total of 700 per study arm. Research assistants were trained to review the EMR for information related to screening and diagnosis of T2D. In the case of multiple visits by the same patient during the study period, the EMR was eligible for review once. The secondary outcome was the percentage of youths who had laboratory tests ordered and completed (screening). Whether a patient underwent screening for T2D was identified as yes when an FPG or an $\mathrm{HbA}_{1 \mathrm{c}}$ level or both were documented in the EMR.

\section{Sample Size and Power Estimation}

We estimated the real screening rate to be approximately $10 \%$ in our clinics under standard practice. Based on a literature review, we expected that more than $20 \%$ of the youths 10 years or older would have a BMI at or above the 85th percentile and at least 2 risk factors for T2D. ${ }^{16,17}$ We would have $80 \%$ power to detect a $10 \%$ difference in the proportion of children who would undergo screening for T2D between the intervention and control groups with a total effective sample size of 438 patients. Because the randomization was at the clinic level, responses from patients in the same clinic were likely correlated, causing a decrease in analytical power. The magnitude of power reduction depends on the level of heterogeneity of the clinical sites; such heterogeneity is often characterized by the intraclinic correlation. Although we did not anticipate significant variability in the 4 clinics, we assumed intraclinic correlation of no more than 0.006 . Using this conservative estimate, we needed to review the EMRs of 317 children per clinic. To accommodate a 10\% rate of missing BMI data, we increased the sample size to 350 per clinic.

\section{Statistical Analysis}

Baseline characteristics of the participants were compared using the $\mathrm{X}^{2}$ test or the Fisher exact test for categorical outcomes and the Wilcoxon rank sum test for age because the distribution was skewed. Logistic regression models estimated associations between the intervention and the odds of screening. Clinic-level random intercepts accommodated the potential dependence of responses from in the same clinic. We did not expect correlation due to clustering of participants in clinics. Covariates (age, sex, race, and insurance) were screened for inclusion by testing whether the groups showed a difference at $P<.10$. Group differences in primary and secondary outcomes were adjusted for age, sex, race, and insurance when a covariate was significant at $P<.10$. Analyses were performed using SAS software (version 9.4; SAS Institute Inc).

\section{Results}

This study included 1423 EMRs abstracted for eligibility. To assess the reliability of EMR abstraction, a random sample of $20 \%$ of the records was abstracted twice. The interrater reliability was $93 \%$, and the $\mathrm{k}$ statistic was 0.87 . Of these, 54 (3.8\%) were missing BMI data and were excluded, leaving 1369 for analysis (712 boys [52.0\%] and 657 girls [48.0\%]; median [interquartile range] age, 12.9 [11.2-15.3]). Of these, 663 patients $(48.4 \%$ ) had a BMI at or above the 85 th percentile. Demographic characteristics of the eligible patients are shown in Table 1. Differences between the control and intervention groups were found for age (median [interquartile range] age, 12.6 [11.3-14.5] vs 13.4 [11.2-15.8] years), race, and insurance. Control clinics had a greater proportion of Hispanic patients (243 [35.5\%] vs 192 [28.1\%]), and intervention clinics had a greater proportion of black patients (336 [49.1\%] vs 376 [55.1\%]) (Table 1). Intervention clinics had more insurance marked as self-pay, other, or none (51 [7.8\%] vs 99 [15.2\%]). When demographic characteristics of the subgroup who met the criteria for screening for T2D were compared, we found no difference in age or insurance between control and intervention clinics, whereas the race difference (black, 135 [47.9\%] vs 150 [53.0\%]; Hispanic, 126 [44.7\%] vs 99 [35.0\%]) remained (Table 1 ).

The proportion of youths meeting BMI criteria and having at least 2 other risk factors for T2D was 565 of 1369 (41.3\%). This proportion did not differ between control (282 of 684 patients [41.2\%]) and intervention (283 of 685 [41.3\%]) sites. This finding was our primary outcome, and therefore the CHICA T2D module did not increase the proportion who had documented risk factors for T2D.

One hundred thirty-two patients underwent screening for T2D, resulting in a screening rate for the entire study population of $9.6 \%$. The adjusted odds ratio of screening in the intervention group was 3.7 (95\% CI, 1.8-7.7) (Table 2). Among the 565 youths meeting criteria, physicians ordered any screening test for T2D for 115 (20.4\%). The adjusted odds ratio for the intervention group was 4.6 (95\% CI, 1.5-14.7) compared with the control group (Table 2).

We found a low rate of ordering FPG for screening (Table 2). None of the documented FPG levels was greater than $125 \mathrm{mg} / \mathrm{dL}$ (diabetes range). One of 3 control patients (33.3\%) who underwent FPG screening had an FPG level in the prediabetes range, and 2 of 9 intervention patients (22.2\%) who underwent FPG screening had FPG levels in the prediabetes range. 


\begin{tabular}{|c|c|c|c|c|}
\hline \multirow[b]{2}{*}{ Characteristic } & \multicolumn{2}{|l|}{$\begin{array}{l}\text { Randomized Group, } \\
\text { No. (\%) }\end{array}$} & \multicolumn{2}{|c|}{$\begin{array}{l}\text { Criteria-Eligible Randomized Group, } \\
\text { No. }(\%)^{\mathrm{a}}\end{array}$} \\
\hline & $\begin{array}{l}\text { Control } \\
(n=684)\end{array}$ & $\begin{array}{l}\text { Intervention } \\
(\mathrm{n}=685)\end{array}$ & $\begin{array}{l}\text { Control } \\
(\mathrm{n}=282)\end{array}$ & $\begin{array}{l}\text { Intervention } \\
(\mathrm{n}=283)\end{array}$ \\
\hline Age, median (IQR), y & $12.6(11.3-14.5)$ & $13.4(11.2-15.8)$ & $12.6(11.3-14.5)$ & $13.1(11.1-15.7)$ \\
\hline \multicolumn{5}{|l|}{ Sex } \\
\hline Male & $371(54.2)$ & $341(49.8)$ & $138(48.9)$ & $130(45.9)$ \\
\hline Female & $313(45.8)$ & $344(50.2)$ & $144(51.1)$ & $153(54.1)$ \\
\hline \multicolumn{5}{|l|}{ Race $^{\text {b }}$} \\
\hline Black & $336(49.1)$ & $376(55.1)$ & 135 (47.9) & $150(53.0)$ \\
\hline Hispanic & $243(35.5)$ & $192(28.1)$ & $126(44.7)$ & $99(35.0)$ \\
\hline White & $59(8.6)$ & $55(8.1)$ & $12(4.3)$ & $13(4.6)$ \\
\hline Other/unknown & $46(6.7)$ & $60(8.8)$ & $9(3.2)$ & $21(7.4)$ \\
\hline \multicolumn{5}{|l|}{ Insurance ${ }^{c}$} \\
\hline Commercial & $42(6.4)$ & $35(5.4)$ & $17(6.3)$ & $13(4.8)$ \\
\hline Medicaid & $560(85.8)$ & $519(79.5)$ & $227(84.1)$ & $222(82.2)$ \\
\hline Self-pay & $25(3.8)$ & $36(5.5)$ & $12(4.4)$ & $15(5.6)$ \\
\hline Other & $25(3.8)$ & $53(8.1)$ & $14(5.2)$ & $17(6.3)$ \\
\hline None & $1(0.2)$ & $10(1.5)$ & 0 & $3(1.1)$ \\
\hline
\end{tabular}

\begin{tabular}{|c|c|c|c|c|}
\hline \multirow[b]{2}{*}{ Outcome } & \multicolumn{2}{|c|}{ Randomization Group, No./Total No. (\%) } & \multirow{2}{*}{$\begin{array}{l}\text { Unadjusted } \\
\text { OR }\end{array}$} & \multirow{2}{*}{$\begin{array}{l}\text { Adjusted OR } \\
(95 \% \mathrm{Cl})\end{array}$} \\
\hline & Control & Intervention & & \\
\hline \multicolumn{5}{|l|}{ T2D screening rate } \\
\hline Entire study population & $33 / 684(4.8)$ & $99 / 685(14.4)$ & 3.3 & $3.7(1.8-7.7)^{\mathrm{a}}$ \\
\hline $\begin{array}{l}\text { Study population with } \geq 2 \text { risk } \\
\text { factors }\end{array}$ & $26 / 282(9.2)$ & $89 / 283(31.4)$ & 4.5 & $4.6(1.5-14.7)^{\mathrm{b}}$ \\
\hline \multicolumn{5}{|l|}{ FPG test } \\
\hline Ordered & $13 / 282(4.6)$ & $12 / 283(4.2)$ & 0.9 & $1.1(0.5-2.7)^{\mathrm{b}}$ \\
\hline Result documented & $3 / 13(23.1)$ & $9 / 12(75.0)$ & 10.0 & $10.0\left(1.7-57.8^{c}\right.$ \\
\hline \multicolumn{5}{|l|}{$\mathrm{HbA}_{1 \mathrm{c}}$ test } \\
\hline Ordered & $25 / 282(8.9)$ & $73 / 283(25.8)$ & 3.6 & $3.7(1.5-9.3)^{\mathrm{b}}$ \\
\hline Result documented & $16 / 25(64.0)$ & $63 / 72(87.5)$ & 3.9 & $3.9(0.6-24.3)^{c}$ \\
\hline Result in prediabetes range & $5 / 16(31.2)$ & $13 / 63(20.6)$ & 0.6 & $0.6(0.3-1.1)^{c}$ \\
\hline \multicolumn{5}{|l|}{ Follow-up } \\
\hline Scheduled & $201 / 282(71.3)$ & $153 / 283(54.1)$ & 0.5 & $0.5(0.2-1.3)^{b}$ \\
\hline Attended & 38/201 (18.9) & $45 / 153(29.4)$ & 1.8 & $1.8(1.5-2.2)^{\mathrm{c}}$ \\
\hline
\end{tabular}

Abbreviation: IQR, interquartile range.

a Includes 565 patients who met criteria of a body mass index at or above the 85 th percentile and 2 or more other risk factors.

${ }^{b}$ Data were missing for 2 patients in the randomized intervention group.

c Data were missing for 31 patients in the randomized control group, 32 patients in the randomized intervention group, 12 patients in the criteria-eligible randomized control group, and 13 patients in the criteria-eligible randomized intervention group.
Abbreviations: FPG, fasting plasma glucose; $\mathrm{HbA}_{1 \mathrm{c}}$, hemoglobin $\mathrm{A}_{1 \mathrm{c}}$; $\mathrm{OR}$, odds ratio; T2D, type 2 diabetes.

${ }^{\text {a }}$ Adjusted for age, sex, race, and insurance.

${ }^{\mathrm{b}}$ Adjusted for race.

c Not adjusted owing to small sample size.
The rate of ordering $\mathrm{HbA}_{1 \mathrm{c}}$ assessment among those meeting ADA criteria was higher than that for FPG assessment (Table 2). Ninety-eight of 565 eligible youths (17.3\%) underwent $\mathrm{HbA}_{1 \mathrm{c}}$ screening. One of the documented $\mathrm{HbA}_{1 \mathrm{c}}$ levels was at least $6.5 \%$ (diabetes range) in the intervention group. Of the control patients undergoing screening, $5(31.2 \%)$ had $\mathrm{HbA}_{1 \mathrm{c}}$ levels ranging from $5.7 \%$ to less than $6.5 \%$ (prediabetes range), and 13 of 63 intervention patients (20.6\%) undergoing screening had $\mathrm{HbA}_{1 \mathrm{c}}$ levels in the prediabetes range. No patients were scheduled for OGTT.

The proportion of youths who were scheduled for a follow-up appointment with their pediatrician is shown in Table 2 . The proportions of youths who actually attended a scheduled follow-up appointment were 38 of 201 control patients (18.9\%) and 45 of 153 intervention patients (29.4\%). One patient was referred to pediatric endocrinology.

\section{Discussion}

The CHICA T2D module more than quadrupled the rates of screening for T2D among youths with a BMI at or above the 85 th percentile and 2 or more risk factors at well-care visits, as recommended by the ADA guidelines. The CHICA T2D module was also associated with greater attendance at follow-up appointments. The intervention did not lead to more patients being diagnosed with prediabetes or T2D, but our study was not powered to detect changes in clinical outcomes. The CHICA system is unique because it permits us to insert guideline-based care into existing clinic practices in a format that integrates easily into routine pediatric care. The CHICA T2D module can therefore overcome many barriers to the T2D screening process. 
Adding telephone reminders to the CHICA T2D module was associated with a greater likelihood of attending follow-up appointments. These automated patient reminders are likely to improve service delivery and to provide benefit to patients. ${ }^{18}$ Computer decision support systems have been shown to improve adherence to practice recommendations in pediatric primary care and hospital settings. ${ }^{9,19-22}$ However, such systems are only beginning to be implemented for patientcentered medicine based on information available in the EMR. ${ }^{10}$ Screening for T2D in youths has not been studied before using this technology. Our findings not only highlight the potential effect of computer decision support for pediatricians caring for populations at high risk for T2D but also set the stage for introducing these systems in other EMRs and for other chronic conditions.

This population was enriched with youth of minority race or ethnicity with a high rate of overweight and obesity (BMI $\geq 85$ th percentile). In comparison, the 2011 to 2012 National Health and Nutrition Examination Survey data for nonHispanic black youths showed that $38.1 \%$ aged 6 to 11 years and $39.8 \%$ aged 12 to 19 years had a BMI at or above the 85 th percentile; data for Hispanic youths showed that $46.2 \%$ aged 6 to 11 years and $38.1 \%$ aged 12 to 19 years had a BMI at or above the 85th percentile. ${ }^{23}$ The proportion of youths meeting BMI criteria and having at least 2 other risk factors for T2D in our study was $41.3 \%$. However, fewer than half of the youths who met this criterion had laboratory tests performed. Even with our intervention, only 73 (25.8\%) of 283 youths known to be at risk for T2D had orders for measurement of $\mathrm{HbA}_{1 \mathrm{c}}$ level. $\mathrm{Al}$ though significantly improved compared with the control group, this rate is still quite low. Rates of prediabetes (5 [31.2\%] of 16 control patients and 13 [20.6\%] of 63 intervention patients) and T2D (0 of 16 control patients and 1 [1.6\%] of 63 intervention patients) in youths undergoing screening in this study were similar to those of previous reports in similar populations. ${ }^{24,25}$ Thus, if a larger proportion had undergone screening, more individuals likely would have received a diagnosis and been scheduled for follow-up. Low rates of screening may reflect the lack of effective treatment methods and resources for T2D prevention in pediatrics. Comprehensive, family-inclusive behavior modification programs are limited, but some evidence of benefit exists. ${ }^{26}$ However, such programs are not widely available, not covered by insurance, and often not accessible by the target population. ${ }^{27,28}$

Physicians opted to use measurement of $\mathrm{HbA}_{1 \mathrm{c}}$ level as the preferred screening test. Use of this test reflects convenience and increasing recognition of published clinical guidelines en- dorsing $\mathrm{HbA}_{1 \mathrm{c}}$ level measurement as an appropriate screening test. ${ }^{4,13,29}$ Measurement of $\mathrm{HbA}_{1 \mathrm{c}}$ level has low sensitivity and specificity when compared with OGTT for diagnosing T2D; but as we observed, OGTT is not used in clinical practice. ${ }^{30,31}$ Levels of $\mathrm{HbA}_{1 \mathrm{c}}$ and FPG reflect important, but different, physiologic aspects of glucose homeostasis. The FPG level is often not elevated in early T2D, whereas hyperglycemia occurs only in the postprandial state. ${ }^{15}$ In addition, the $\mathrm{HbA}_{1 \mathrm{c}}$ level is more persistent over time. ${ }^{31}$ Based on ease and acceptability, $\mathrm{HbA}_{1 \mathrm{c}}$ testing is preferred, although research is necessary to determine optimal screening strategies for youth populations at high risk for T2D.

\section{Limitations}

This study has limitations that warrant consideration. Although we conducted a large randomized clinical trial, only 4 clinics were involved. We cannot ensure that no differences between the control and intervention groups existed in BMI distribution, although all patients in this study had BMI at or above the 85th percentile or no differences in other coexisting conditions. We also could not determine correlation due to clustering of patients in clinics. The age distribution of the patients was skewed toward younger adolescents because many patients older than 15 years were seen in a separate clinic that did not use CHICA. This separation may have led to lower rates of prediabetes and T2D detected by screening procedures. The CHICA system is also currently used only in Eskenazi Health and Indiana University Health primary care settings. We are working to provide CHICA as a web service that can interface with commercial EMR systems. For dissemination, current ADA recommendations, which treat OGTT results and FPG and $\mathrm{HbA}_{1 \mathrm{c}}$ levels as equivalent and do not recommend sequential testing in asymptomatic individuals, should be used. ${ }^{32}$ The FPG cut point of $100 \mathrm{mg} / \mathrm{dL}$ should be used instead of $95 \mathrm{mg} / \mathrm{dL}$, as was used in this study.

\section{Conclusions}

Use of a computerized clinical decision support system to automate the identification and screening for T2D can help overcome barriers to the screening process. The system significantly increased rates of screening among youths who met the ADA criteria and adherence to follow-up appointments with primary care clinicians. Whether the system can help improve health outcomes in youth diagnosed with prediabetes or T2D remains to be determined.

\section{ARTICLE INFORMATION}

Accepted for Publication: October 26, 2016.

Published Online: February 13, 2017.

doi:10.1001/jamapediatrics.2016.4207

Author Contributions: Drs Hannon and Carroll had full access to all the data in the study and take responsibility for the integrity of the data and the accuracy of the data analysis.

Study concept and design: Hannon, Saha, Downs, Carroll.
Acquisition, analysis, or interpretation of data: All authors.

Drafting of the manuscript: Hannon. Critical revision of the manuscript for important intellectual content: All authors.

Statistical analysis: Saha. Obtained funding: Hannon, Saha, Carroll. Administrative, technical, or material support: Dugan, McKee, Downs, Carroll.

Conflict of Interest Disclosures: None reported.
Funding/Support: This study was supported by grant R01DK092717 from the National Institute of Diabetes and Digestive and Kidney Diseases. This project used REDCap, a service provided by the Indiana Clinical and Translational Sciences Institute and funded in part by Clinical and Translational Sciences Award UL1TR001108 from the National Institutes of Health, National Center for Advancing Translational Sciences.

Role of the Funder/Sponsor: The funding sources had no role in the design and conduct of the study; 
collection, management, analysis, and interpretation of the data; preparation, review, or approval of the manuscript; and decision to submit the manuscript for publication.

Additional Contributions: The Child Health Informatics Research and Development Laboratory and the Pediatric Research Network group at the Indiana University School of Medicine collected data for this study. No compensation was received for this work.

\section{REFERENCES}

1. American Diabetes Association. Type 2 diabetes in children and adolescents. Diabetes Care. 2000; 23(3):381-389.

2. American Diabetes Association. 4. Prevention or delay of type 2 diabetes. Diabetes Care. 2016;39 (suppl 1):S36-S38.

3. Anand SG, Mehta SD, Adams WG. Diabetes mellitus screening in pediatric primary care. Pediatrics. 2006;118(5):1888-1895.

4. Lee JM, Eason A, Nelson C, Kazzi NG, Cowan AE, Tarini BA. Screening practices for identifying type 2 diabetes in adolescents. J Adolesc Health. 2014;54 (2):139-143.

5. Biondich PG, Downs SM, Anand V, Carroll AE. Automating the recognition and prioritization of needed preventive services: early results from the CHICA system. AMIA Annu Symp Proc. 2005:51-55.

6. Bauer NS, Carroll AE, Downs SM. Understanding the acceptability of a computer decision support system in pediatric primary care. J Am Med Inform Assoc. 2014;21(1):146-153.

7. Anand V, Biondich PG, Liu G, Rosenman M, Downs SM. Child Health Improvement Through Computer Automation: the CHICA system. Stud Health Technol Inform. 2004;107(pt 1):187-191.

8. Downs SM, Biondich PG, Anand V, Zore M, Carroll AE. Using Arden Syntax and adaptive turnaround documents to evaluate clinical guidelines. AMIA Annu Symp Proc. 2006:214-218.

9. Carroll AE, Biondich PG, Anand V, et al. Targeted screening for pediatric conditions with the CHICA system. J Am Med Inform Assoc. 2011;18(4):485-490.

10. Anand V, Carroll AE, Biondich PG, Dugan TM, Downs SM. Pediatric decision support using adapted
Arden Syntax [published online October 1, 2015]. Artif Intell Med. doi:10.1016/j.artmed.2015.09.006

11. Biondich PG, Grannis SJ. The Indiana Network for Patient Care: an integrated clinical information system informed by over thirty years of experience. $J$ Public Health Manag Pract. 2004;(suppl):S81-S86.

12. Lee JM, Wu EL, Tarini B, Herman WH, Yoon E. Diagnosis of diabetes using hemoglobin A1c: should recommendations in adults be extrapolated to adolescents? J Pediatr. 2011;158(6):947-952.e1, 3.

13. Love-Osborne KA, Sheeder J, Svircev A, Chan C, Zeitler P, Nadeau KJ. Use of glycosylated hemoglobin increases diabetes screening for at-risk adolescents in primary care settings. Pediatr Diabetes. 2013;14(7):512-518

14. American Diabetes Association. Diagnosis and classification of diabetes mellitus. Diabetes Care 2014;37(suppl 1):S81-S90.

15. Hannon TS, Arslanian SA. The changing face of diabetes in youth: lessons learned from studies of type 2 diabetes. Ann N Y Acad Sci. 2015;1353:113-137.

16. Drobac S, Brickman W, Smith T, Binns HJ. Evaluation of a type 2 diabetes screening protocol in an urban pediatric clinic. Pediatrics. 2004;114(1) 141-148.

17. Kong AS, Williams RL, Smith M, et al; RIOS Net Clinicians. Acanthosis nigricans and diabetes risk factors: prevalence in young persons seen in southwestern US primary care practices. Ann Fam Med. 2007;5(3):202-208.

18. Guy R, Hocking J, Wand H, Stott S, Ali H, Kaldor $J$. How effective are short message service reminders at increasing clinic attendance? a meta-analysis and systematic review. Health Serv Res. 2012;47(2):614-632.

19. Carroll AE, Bauer NS, Dugan TM, Anand V, Saha C, Downs SM. Use of a computerized decision aid for ADHD diagnosis: a randomized controlled trial. Pediatrics. 2013;132(3):e623-e629.

20. Carroll AE, Bauer NS, Dugan TM, Anand V, Saha C, Downs SM. Use of a computerized decision aid for developmental surveillance and screening a randomized clinical trial. JAMA Pediatr. 2014;168 (9):815-821.

21. Carroll AE, Biondich P, Anand V, Dugan TM, Downs SM. A randomized controlled trial of screening for maternal depression with a clinical decision support system. J Am Med Inform Assoc. 2013:20(2):311-316.

22. Koves IH, Leu MG, Spencer S, et al; Diabetic Ketoacidosis Guideline Development Workgroup. Improving care for pediatric diabetic ketoacidosis. Pediatrics. 2014;134(3):e848-e856.

23. Ogden CL, Carroll MD, Kit BK, Flegal KM. Prevalence of childhood and adult obesity in the United States, 2011-2012. JAMA. 2014;311(8): 806-814

24. Sinha R, Fisch G, Teague B, et al. Prevalence of impaired glucose tolerance among children and adolescents with marked obesity. N Engl J Med. 2002;346(11):802-810.

25. May AL, Kuklina EV, Yoon PW. Prevalence of cardiovascular disease risk factors among US adolescents, 1999-2008. Pediatrics. 2012;129(6): 1035-1041.

26. Savoye M, Caprio S, Dziura J, et al. Reversal of early abnormalities in glucose metabolism in obese youth: results of an intensive lifestyle randomized controlled trial. Diabetes Care. 2014;37(2):317-324.

27. American Diabetes Association. 11. Children and adolescents. Diabetes Care. 2016;39(suppl 1): S86-S93.

28. Ratner RE. The imperative to prevent diabetes. Diabetes Care. 2012;35(12):2417-2418.

29. Springer SC, Silverstein J, Copeland K, et al; American Academy of Pediatrics. Management of type 2 diabetes mellitus in children and adolescents. Pediatrics. 2013;131(2):e648-e664.

30. Nowicka P, Santoro N, Liu H, et al. Utility of hemoglobin $\mathrm{A}_{1 \mathrm{c}}$ for diagnosing prediabetes and diabetes in obese children and adolescents. Diabetes Care. 2011;34(6):1306-1311.

31. Buse JB, Kaufman FR, Linder B, Hirst K, El Ghormli L, Willi S; HEALTHY Study Group. Diabetes screening with hemoglobin $A_{1 c}$ versus fasting plasma glucose in a multiethnic middle-school cohort. Diabetes Care. 2013;36(2): 429-435.

32. American Diabetes Association. 2. Classification and diagnosis of diabetes. Diabetes Care. 2016;39 (suppl 1):S13-S22. 